\title{
LA ÉTICA DE ARISTÓTELES EN LA EVOLUCIÓN DE LA CULPA JURÍDICA. UNA REVISIÓN A PROPÓSITO DE LA PREVISIBILIDAD*
}

\author{
ARISTOTLE'S ETHICS IN THE EVOLUTION OF THE LEGAL \\ NEGLIGENCE: A REVIEW ABOUT FORESEEABILITY
}

Sonia INOSTROZA ADASME ${ }^{* *}$

Resumen:

En el siglo IV a.C., Aristóteles aborda la diferencia entre $\dot{\alpha} \mu \alpha \dot{\alpha} \rho \tau \eta \mu \alpha$ (negligencia) y $\alpha \delta \measuredangle \kappa \eta \mu \alpha$ (dolo). En consecuencia, distingue entre los actos voluntarios e involuntarios para de esta manera llegar al razonamiento 200 años antes que los juristas romanos.

Si bien es cierto, no se puede afirmar una relación equivalente entre la culpa, tal como ésta fue concebida en el mundo griego, con el pensamiento del jurisconsulto romano, sí es posible encontrar particularmente en el tratamiento de los actos involuntarios la huella, el germen o esencia de la culpa estricta. $^{1}$

\section{Palabras claves:}

Aristóteles, culpa, negligencia, dolo, previsibilidad.

\begin{abstract}
:
In the 4th century $B C$, Aristotle addressed the difference between $\dot{\alpha} \mu \alpha \dot{\rho} \tau \eta \mu \alpha$ (negligence) and $\alpha \delta \delta$ ik $\mu \alpha$ (wrongdoing). Consequently, he distinguishes between voluntary and involuntary acts so as to arrive at such reasoning 200 years before Roman jurists did.

* Artículo recibido el 28 de diciembre de 2019 y aceptado para su publicación el 12 de mayo de 2020.

** Magister en derecho, Pontificia Universidad Católica de Valparaíso, Chile. Doctoranda en derecho, Universidad de los Andes, Chile. Contacto: sainostroza@miuandes.cl. Orcid: https://orcid.org/0000-0002-2437-4782.

${ }^{1}$ Cristián Aedo Barrena, "Raíces griegas de la noción romana de culpa", Revista de estudios histórico-jurídicos, Chile, 35, 2013, pp. 39-80.
\end{abstract}




\section{SONIA INOSTROZA ADASME}

Although it is true that it is not possible to affirm an equivalent relationship between negligence, as it was conceived in the Greek world, with the thought of Roman jurisconsultants, it is possible to find the trace, the germ or essence of strict negligence, particularly in the treatment of involuntary acts.

\section{Keywords:}

Aristotle, Fault, Negligence, Wrongdoing, Foreseeability. 
SUMARIO: I. Introducción. II. El concepto de culpa en Aristóteles. III. El germen de la culpa aristotélica en el derecho romano. IV. Tratamiento doctrinario de la previsibilidad en la culpa extracontractual durante la época medieval. $V$. Tratamiento en la época renacentista. VI. Codificación y sus antecedentes relativos a la previsibilidad. VII. Conclusiones. VIII. Referencias.

\section{INTRODUCCIÓN}

Tal como señala el profesor Joaquín García Huidobro en su tesis doctoral de derecho: "La ética a Nicómaco constituye una de las obras fundamentales de la tradición filosófico moral de Occidente, tanto por su importancia como porque está en la base de esta tradición, de algún modo la funda". ${ }^{2}$

Es así como establece el cimiento de un abanico de materias que hoy se expanden de forma trasversal en distintas ciencias. Por consiguiente, frente a esta afirmación no puede estar ausente en nuestra investigación.

La culpa en el concepto aristotélico se asimila en su estado prístino a una mancha moral y de esa manera la podemos advertir en Ética a Nicómaco, en donde $\dot{\alpha} \mu \alpha \rho \tau i ́ \alpha$ (hamartía) se describe como una de las tres ofensas que un hombre puede inferir a otro. Así las cosas, harmatía es una ofensa cometida por ignorancia (cuando la persona afectada o el resultado no son lo que el agente suponía que eran), verbigracia: la harmatía de Edipo fue matar a su padre pues aunque sabía que estaba perpetrando un asesinato, ignoraba que el hombre era un rey y su padre...

Por otra parte, la noción de que la culpa presupone la previsibilidad del daño está también presente en el pensamiento del Estagirita, y por eso afirma que quien con tal resultado actúa "sin previa

2 Joaquín García-Huidobro, La recepción de la doctrina aristotélica de lo justo natural y lo justo legal en los comentaristas medievales de la Ética a Nicómaco, Tesis doctoral presentada en la Facultad de Derecho de la Universidad Austral, Buenos Aires, 2015. 
deliberación", esto es, sin prever las consecuencias de suyo previsibles, comete injusticia aunque él mismo no sea injusto y malo.

Para nuestros fines, lo interesante es observar la identificación de $\dot{\alpha} \mu \alpha \rho \tau i ́ \alpha$ (hamartía) у $\dot{\alpha} \mu \alpha ́ \alpha \tau \eta \mu \alpha$ (hamártema) ${ }^{3}$ con la culpa romana que es aquel factor de atribución que acogerá las ideas centrales de este trabajo, analizando la evolución de este elemento desde el siglo IV a. C. hasta la codificación decimonónica.

\section{El CONCEPTO DE CULPA EN ARISTÓTELES}

Ya antes de que apareciera el concepto en su significado jurídico, ligado a la interpretación jurisprudencial de la lex Aquilia de damno promulgada como plebiscito el año 286 a. C., los filósofos griegos habían reflexionado sobre el concepto de culpa, y a pesar de que abordan la cuestión desde un punto de vista ontológico y no jurídico, podemos afirmar que tales consideraciones fueron conocidas y tenidas en cuenta para el aprovechamiento de ellas en la construcción del delito de daño. ${ }^{4}$

Nuestro análisis partirá de Aristóteles, que en su Ética a Nicómaco describe y diferencia una serie de actos que, realizados por el hombre, pueden acarrear daño a otra persona, y dan lugar a que se practique la justicia correctiva, llamada también conmutativa o reparadora ${ }^{5}$, mediante la cual propendemos a restaurar una igualdad, ocasionalmente rota, en la relación que media entre dos personas, la del dañador y la de la víctima. ${ }^{6}$ Transcribiremos los pasajes que nos parecen más pertinentes.

(Los legisladores) castigan el mismo hecho de ignorar, si el delincuente parece responsable de la ignorancia; así a los embriagados se les impone

3 José Ferrater Mora, Diccionario de filosofía: José Ferrater Mora, 1a. ed., Madrid,

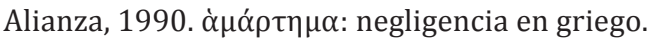

4 Enrique Barros Bourie, "La culpa en la responsabilidad civil”, Ensayos jurídicos Universidad Alberto Hurtado, Chile, 1, 2005, 6; Alejandro Guzmán, Historia de la codificación civil en Iberoamérica, Thomson Aranzadi, 2006.

5 Josef Pieper, Las Virtudes Fundamentales, 9a. ed., Madrid, Rialp, 2017, 144.

6 Aristoteles, Ética a Nicómaco, 2a. ed., Madrid, Tecnos., V., 1132 a. 7. 


\section{LA ÉTICA DE ARISTÓTELES EN LA EVOLUCIÓN DE LA CULPA JURÍDICA...}

doble castigo, pues el origen está en ellos mismos, ya que eran dueños de no embriagarse, y la embriaguez fue causa de su ignorancia. Castigan también a los que ignoran ciertas materias legales que deben saberse y no son difíciles; y lo mismo en los casos en los que la ignorancia parece tener por causa la negligencia, porque estaba en su poder no ser ignorantes, ya que eran dueños de poner atención. ${ }^{7}$

Cuando el daño se produce de un modo imprevisible es un infortunio; cuando se produce no de un modo imprevisible, pero sí sin malicia, es un error (pues uno yerra cuando el origen de la culpa está en él, pero es puro infortunio cuando procede de fuera). Cuando uno actúa a sabiendas pero sin previa deliberación, se comete una injusticia.

... Cuando los hombres cometen estos daños y equivocaciones, obran injustamente y son injusticias, pero no por ello los autores son injustos y malos, porque el daño no tiene por causa la maldad; pero cuando actúan con intención, son injustos y malos. ${ }^{8}$

Diversas consideraciones podemos hacer a partir de los pasajes transcritos: ante todo, que el Estagirita ${ }^{9}$ distingue con precisión tres, o hasta cuatro clases de actos dañosos, en relación con la conciencia que de ellos tenía el autor:

a) Aquellos cometidos por causa de ignorancia y en lo que el autor no podía prever el resultado (ATIXEMA). Tales son los que en la posterior doctrina romana de la responsabilidad, pueden asimilarse al caso fortuito o al periculum.

b) Aquellos cometidos en virtud de la ignorancia del autor, pero cuyo resultado dañoso podía razonablemente ser previsto (HAMARTÍA o HAMÁRTEMA): ellos son los que más propiamente se pueden asimilar al concepto jurídico de culpa o negligencia.

c) Aquellos que el actor, realiza con conocimiento del daño que causa o puede causar, pero cuyo proceder aparece obnubilado por un impulso pasional (ADIKEMA). ${ }^{10}$

7 Aristóteles, Ética a Nicómaco, 2a. ed., Madrid, Tecnos, III., 1113 b. 29.

8 Aristóteles, Ética a Nicómaco, 2a. ed., Madrid, Tecnos, III., 1135 b. 20.

9 José Ferrater Mora, Diccionario de filosofía, Madrid, Alianza, 1990.

$10 \mathrm{Al}$ respecto véase Bernhard Kluber, citado por Cristián Aedo Barrena, La culpa aquiliana, Thomson Reuters, 2018, pp. 23 y ss. 
d) Por último, los actos conscientes y deliberadamente perversos (MOCHTEROS).

Una segunda consideración, particularmente extraída del último de los párrafos transcritos: Aristóteles distingue claramente, entre los actos que causan daño, aquellos que merecen un reproche moral frente a los que solo son reprochables desde un punto de vista jurídico, ya que "hay autores que obran injustamente, pero no por ello son injustos y malos", al paso que cuando actúan con intención, "son injustos y malos".

Hemos indicado que el concepto aristotélico de hamartía es el que mejor se puede asimilar a la idea técnica de culpa, pero conviene no perder de vista que, desde un punto de vista filosófico, enriquecido modernamente por las investigaciones del psicoanálisis, puede llegarse a conclusiones más específicas. Varios autores han tratado la culpa a través de ese prisma, y en general, tienden a extender el concepto no exclusivamente a la negligencia sino que comprenden también el dolo dentro de la denominación: en verdad, el término hamartía, identificado preferentemente con negligencia, toma en un sentido más coloquial el significado de cualquier acto reprobable cometido voluntariamente, de manera que comprende también el concepto de ADIKIA o ADIKEMA: así se explica, por ejemplo, la inclusión de este último término en Inst.4,4,pr. ${ }^{11}$

\section{Culpa normal y culpa mórbida}

Este concepto omnicomprensivo de culpa nos conduce al análisis desarrollado, desde distintos ángulos, por Ricoeur y Lacroix: expresado el primero a través de los símbolos del psicoanálisis, describe la culpa como una mancha recibida por el hombre desde afuera, y que compromete su libertad, condición necesaria de su propia caída. Entiende la libertad de una manera única, indivisible, total, tal como la entendían los antiguos, para quienes la libertad es la condición negativa de no ser esclavo - ya sea de un amo externo o de sus pro-

11 Castresana, Amelia, Nuevas lecturas de la responsabilidad aquiliana, Universidad de Salamanca, 2001, pp. 59 y ss. 


\section{LA ÉTICA DE ARISTÓTELES EN LA EVOLUCIÓN DE LA CULPA JURÍDICA...}

pias carencias morales internas. No hay para ellos "libertades" sino sólo una, que es el control que el hombre tiene sobre sus propios actos y pasiones. ${ }^{12}$ La culpa, la mancha de la que el hombre ha de ocuparse a fin de limpiarla, tiene dos expresiones posibles, que Lacroix denomina respectivamente "culpa mórbida" y "culpa normal” y que dicho autor relaciona a dos sentimientos del hombre: la primera, al remordimiento; la segunda, al arrepentimiento. ${ }^{13}$

No podemos dejar de representar dos ejemplos, históricos o mitológicos, de estas dos especies de culpa: la primera de ellas es Edipo, personificado en la célebre tragedia de Esquilo. Su nombre ("Pie hinchado") ya revela la mancha que ata su libertad, y que es la vanidad: movido por ella adelanta, en el camino, el carro que conducía su padre y que, por cuanto le impedía un paso expedito, desata la ira provocadora del crimen que a la postre resulta ser un parricidio preterintencional. Edipo vive atormentado, y cuando la esfinge le propone una adivinanza salvadora, él le contesta a medias, pues aunque da por respuesta "el hombre", la pregunta de la esfinge aludía a un hombre cojo, de manera que la respuesta plenamente correcta habría sido "yo mismo". Siendo incompleta la respuesta, Edipo no supera las consecuencias de la culpa, y cuando al fin cae en cuenta de la magnitud de su crimen, es ya tarde para la confesión, se hunde en la desesperanza y se arranca los ojos como castigo por "no haber sabido ver" su culpa. Edipo no es víctima del inexorable destino decretado por los dioses (ATE) ${ }^{14}$, sino de su culpa primigenia, que es la vanidad, de la que nunca supo librarse.

En contraste con este ejemplo de culpa mórbida, está el caso de David, rey de Israel, narrado en Samuel, 2,12. David, después de haber incurrido en adulterio con la mujer del jeteo Urías, y a fin de evitar la muerte de su amante, dispone que Urías afronte un peligro mortal en el que efectivamente perece.

12 Ricoeur, Paul, El conflicto de las interpretaciones, trad. de Alejandría Falcón, FCE, 2008. Véase, especialmente, su estudio sobre la simbólica del mal, pp. 245 y ss.

13 Lacroix, Jean, Filosofía de la culpabilidad, trad. de A. Martínez, Revista Barcelona, 1977, pp. 20-22.

14 Dodds, Eric, Los griegos y lo irracional, trad. de María Aranjo, Madrid, Alianza Editorial, 1951, pp. 19 y ss. 
El profeta Natán relata a David una parábola intencionada, donde un hombre rico se apodera de la única oveja que tenía un pobre y a la que amaba como a una hija: la mata para aderezarla y ofrecerla en banquete a sus amigos. David, encolerizado, exclama que ese ricachón es reo de muerte, a lo que Natán replica: "tú eres ese hombre". David así reconoce su culpa, hace penitencia durante una semana y vuelve a ser gobernante justo y hombre virtuoso. Así la culpa, que yacía oculta en su inconsciente, sale a la luz, la reconoce y confiesa, gracias a lo cual sobreviene el arrepentimiento y el espíritu convalece.

Aunque el resultado es diverso, ambos paradigmas, el de Edipo y el de David, muestran una misma realidad, cual es el fundamento relacional que tiene el sentimiento de la culpa. Este sentimiento se expresa en un plano que, en sentido amplio, podemos llamar social, porque se concreta y exterioriza inevitablemente, bien en la relación del hombre con Dios, bien en las relaciones humanas intersubjetivas. La mancha que simboliza la culpa proviene de una falta que incide sobre esas relaciones, sea frente a Dios, respecto de quien nos une un deber de amor filial (pietas) o frente a otro ser humano como nosotros, hacia quien por razón de humanidad y por nuestra propia condición de persona, esencialmente gregaria, nos sentimos unidos en una relación de proximidad ("prójimo") que nos impone moralmente, el deber de amor "entre iguales" (dilectio o diligentia) ${ }^{15}$ Por eso el descuido en nuestras relaciones sociales, sobre todo cuando presumiblemente puede tener como resultado una consecuencia dañosa para el prójimo, constituye en sí una falta de amor (negligentia) que también se radica en nosotros como una mancha, necesitada de confesión y reparación para nuestra definitiva salud. Según ya hemos observado, Aristóteles se refiere a la negligencia al describir uno de los casos típicos de hamartía.

Conviene advertir, sin embargo, que Aristóteles menciona la negligencia a propósito de los que "ignoran ciertas materias legales" y aunque estimamos que las palabras del filósofo pueden por igual referirse a las leyes de la polis tanto como a las que los dioses imponen a los hombres al resguardo del amor (agape), la cuestión desde ya

15 Al respecto Lacroix, Filosofía de la culpabilidad, pp. 76-81. 
nos plantea el problema de las relaciones entre culpa moral y culpa jurídica. ${ }^{16}$

No podemos dudar sobre que existen claras diferencias entre ambos géneros de culpa, ya que la culpa jurídica está dirigida a mantener un orden de convivencia social, y más concretamente en el caso de la culpa aquiliana, a retribuir un daño que hemos ocasionado a veces ni siquiera queriéndolo, sino por causa de una ignorancia o imprevisibilidad que revela, si no aversión al prójimo, la ausencia de un amor operativo. Pero tal negligencia es juzgada "socialmente", esto es no en relación a nuestro propio ejercicio de amor (diligentia) sino en comparación a lo que es normal en la conducta de nuestros semejantes.

Por eso para el juez, su misión en tal supuesto está en concordancia con la restauración de la igualdad entre el autor del daño y la víctima, lo cual, como acabamos de decir, incide en el propósito jurídico de mantener el orden social, y no propiamente en el castigo del culpable. La integridad moral de las personas que participan como protagonistas en el litigio no constituye asunto para el juez, ya que el propósito del reproche jurídico no es corregir al culpable, sino restaurar la igualdad: "no importa que un hombre bueno haya despojado a un hombre malo o al revés, o que un hombre bueno o malo hayan cometido adulterio: el derecho trata a ambas partes como iguales, al que comete la injusticia y al que la sufre; al que perjudica y al perjudicado". ${ }^{17}$

Sin embargo, ambos géneros de culpa suponen en su ejecutor una determinada conducta que consiste en no hacer lo que es debido respecto de los otros. ${ }^{18}$ En este sentido, lo que pretende el derecho es el establecimiento de una sanción reparadora destinada a remediar el daño ocasionado por actos provenientes de persona moralmente responsable: por eso el delito de daño no afecta a los que al menos en teoría, carecen de responsabilidad moral, tales como los infantes y los dementes. Sin embargo, la moralidad de dichos actos no la puede conocer el derecho, por cuanto el juez es incapaz de penetrar

16 Lacroix, Filosofía de la culpabilidad, pp. 93-98, 205-108, 122 y ss.

17 Aristoteles, Ética a Nicómaco, 2a. ed., Madrid, Tecnos, V, 1132 a., pp. 3-7.

18 Lacroix, Filosofía de la culpabilidad, pp. 116-118. 
en la conciencia, y por eso se atiene a lo que ordinariamente, en el actuar de "un buen padre de familia" se puede tener como ajustado al orden moral. Así la diligencia, tal como la entienden tanto Aristóteles como nuestra propia legislación, es un modelo de conducta que no está referida a nuestra propia capacidad de amar al prójimo, sino al modelo tan caro a los antiguos que es "el buen padre". ${ }^{19}$

\section{EL GERMEN DE LA CULPA ARISTOTÉLICA EN EL DERECHO ROMANO}

El tratamiento de la culpa, conformado según el modelo aristotélico, va a proporcionar dos interesantes puntos de vista a la jurisprudencia romana:

Ante todo, que la culpa admite ciertas graduaciones. El Estagirita lo insinúa, conforme a un texto más arriba transcrito, en el sentido de que no es igual la culpa de quien actúa obnubilado por una pasión, caso de la adikema, frente a los que actúan por ignorancia, pero pudiendo prevenir el resultado, caso de la hamartía.

Además, el filósofo apunta claramente al requisito de la previsibilidad, ya que cuando el autor, obrando con ignorancia, no pudo prever el resultado, la culpa queda excluida y el hecho simplemente se refiere a un caso fortuito.

\section{La graduación de la culpa}

La graduación de la culpa fue progresivamente acogida entre los juristas romanos en un comienzo a propósito de las "acciones de lealtad recíproca" (bonae fidei), a través de las cuales y en concepto jurisprudencial, el obligado no solo responde por el dolo (como cuando se trata de un delito), sino que está sujeto a un canon más estricto, en cuanto se le exige observar en lo referente al cumplimiento de sus obligaciones, una conducta acorde con lo que entre personas responsables, es propia del "amor fraterno" o "diligentia". ${ }^{20}$

19 Enrique Barros Bourie, "La responsabilidad civil como derecho privado", Estudios Públicos, núm. 112, 2008, p. 312.

20 D'Ors, Derecho Privado Romano, 3a ed., Pamplona, EUNSA, 1977, pp. 501 y ss. 
LA ÉTICA DE ARISTÓTELES EN LA EVOLUCIÓN DE LA CULPA JURÍDICA...

La jurisprudencia clásica no ahondó más en este terreno, pero los textos postclásicos distinguieron, conforme a la utilitas contrahentium, aquellos casos en que la utilidad es solo para el acreedor, y que acarrean para éste responsabilidad exclusivamente en el supuesto de "culpa grave"; si la utilidad es para ambas partes, se mantiene el principio originario de la diligentia o "culpa leve", e inclusive si la utilidad es solo para el deudor, como sucede por ejemplo en el comodato, los bizantinos transformaron la idea clásica de "custodia" en lo que llamaron "culpa levísima" o "exactissima diligentia". ${ }^{21}$

\section{La previsibilidad del daño}

Pero el punto más interesante para la orientación de nuestro trabajo, desarrollado sobre los aspectos que sugieren, en materia de culpa las relaciones entre moral y derecho, está en la cuestión de la previsibilidad, ${ }^{22}$ materia en la que, a partir del ya expuesto criterio de Aristóteles, desarrolla la jurisprudencia romana desde los comienzos de la época clásica.

Hemos de apuntar que este problema fue abordado por los juristas tanto a propósito de la actio legis aquiliae y acciones honorarias complementarias como en relación con los contratos. Respecto de estos, sin embargo, el estudio jurisprudencial se dirige a las consecuencias del incumplimiento doloso, por cuanto los perjuicios previsibles sobrevinientes en tales circunstancias, vienen a incrementar el monto de la indemnización por daño emergente o lucro cesante. ${ }^{23}$ Así pues, y en la medida que nuestro estudio se dirige no exactamente al dolo, sino a la culpa propiamente tal, heredera del con-

21 Véase al respecto: Coll 10.2.1 y D. 9.2.44 (itp). También D. 13.6.5.2, 16.3.2, 19.2.31, todos reelaborados.

22 Para "La ética de Aristóteles en la evolución de la culpa jurídica una revisión a propósito de la previsibilidad", remitimos a nuestro trabajo Sonia Inostroza Adasme, "La previsibilidad en la culpa Aquiliana: ¿evolución o involución? Una revisión doctrinaria y jurisprudencial”, Revista de Derecho, Universidad Católica del Norte, volumen 27, 2020, en prensa.

23 Guzmán, Alejandro, Derecho privado romano, 2a. ed., Santiago de Chile, Legal Publishing, pp. 107 y ss. 
cepto artistotélico de hamartía, la previsibilidad romana debe ser analizada en el ámbito del daño aquiliano.

Quinto M. Scevola, ${ }^{24}$ hacia el año 100 a. C. asimilaba el concepto aquiliano de injuria a la culpa mejor que al dolo, y entendía por ésta precisamente el hecho de que el autor del delito no ha empleado aquella capacidad de las facultades mentales que le habrían permitido prever un daño realmente previsible, lo mismo que si, aun habiéndose previsto el resultado, no ha desplegado el autor toda la actividad que habría sido necesario desarrollar a fin de evitar la aparición del daño. Realmente - al menos respecto de los elementos de conocimiento que nos entregan las fuentes- parece haber sido Quinto Mucio el descubridor del requisito de la previsibilidad, y tratarlo como si fuera un componente imprescindible de la culpa: es lícito pensar que todos los autores posteriores la toman en cuenta a pesar de que no siempre la mencionan, ya que de ninguna manera aparece después discutido o negado ese requisito.

La idea del jurista surge a propósito del siguiente hecho que le fue consultado y que posteriormente quedó plasmado en el Digesto: D.9, 2, 31. (Paul. 10 Sab.):

Si un podador, al tirar una rama de un árbol... mató a un esclavo transeúnte, queda obligado, si la cosa cae en lugar público... Pero también dijo Mucio que, aunque hubiera ocurrido lo mismo en lugar privado, puede demandarse por culpa: pues es culpa lo que pudiendo haber sido previsto por persona diligente no lo fue, o se avisó en un momento en que no podía evitarse el peligro. Según este razonamiento, poco importa que se caminara por lugar público o privado ya que muy frecuentemente se suele pasar por terrenos privados. Pero si no hubiese camino, debe responder tan solo del dolo para que no arroje contra aquel que viere transeúnte, pues no ha de exigírsele culpa cuando no hubiese podido conjeturar si había de transitar alguien por aquel lugar.

El caso que expone Quinto se pronuncia con terminante claridad: el podador ha incurrido en culpa porque debió prever que trabajando en un lugar por donde el tránsito era frecuente, podía llegar a

24 D. 9. 2. 31, Paulo 10 Sab... dijo Mucio que... es culpa lo que pudiendo haber sido previsto por persona diligente, no lo fue... 


\section{LA ÉTICA DE ARISTÓTELES EN LA EVOLUCIÓN DE LA CULPA JURÍDICA...}

suceder lo que efectivamente ocurrió, y da lo mismo que el camino sea público o privado, pues igualmente en uno y en otro se puede prever - conjeturar - el paso de personas. Y a propósito de esta reflexión, propone un concepto de culpa que, como decimos, será tenido por exacto a través de toda la obra jurisprudencial clásica: "es culpa lo que pudiendo haber sido previsto por persona diligente no lo fue, ... pues no ha de exigírsele culpa cuando no hubiese podido conjeturar el peligro". Podemos observar además cómo, en concepto de Mucio, la previsibilidad, en cuanto tiene calidad de elemento configurador de la culpa, exige el mismo criterio de objetividad y abstracción que ésta, pues se refiere a aquello que pudiendo ser previsto por persona diligente no lo fue.

Gayo, ${ }^{25}$ doscientos cincuenta años después de Quinto Mucio, abunda en el mismo sentido conceptual: un mulero conducía una mula, pero por su debilidad, fue incapaz de retener el ímpetu de la bestia y a consecuencia de ello resultó atropellado un esclavo. Gayo hace al mulero responsable de daño aquiliano, desde el momento que "nadie debe asumir un trabajo en el que sabe o debe saber que su debilidad ha de ser peligrosa a otros".

Paulo por fin, el último de los juristas clásicos junto con Ulpiano, insiste en la idea, y hace responsable por la acción de la Lex Aquilia al que cavó hoyos en un camino a fin de cazar osos y ciervos, y en ellos cayó algo ajeno que se deterioró, pero si las trampas se hicieron en otros lugares donde suelen hacerse, no queda obligado, pues no habría sabido o podido prever la ocurrencia del daño. ${ }^{26}$

\section{TRATAMIENTO DOCTRINARIO DE LA PREVISIBILIDAD EN LA CULPA EXTRACONTRACTUAL DURANTE LA ÉPOCA MEDIEVAL}

El esquema romano de la previsibilidad, asociado íntimamente a la culpa en el ámbito de la responsabilidad aquiliana, va a mostrar

25 D. 9,2,8, Gai, 7 ed. prov. Uno que por debilidad no pudo retener el ímpetu de las mulas, las que terminaron atropellando a un esclavo ajeno: quien sabe o debe saber que su debilidad puede ser peligrosa para otro, no debe asumir semejante trabajo.

26 D. 9,2, 28, Paulo 10 Sab. 
cierto giro conforme se manifiesta en las nociones morales y la literatura jurídica a que dará comienzo, por una parte, el descubrimiento irneriano de las fuentes cultas contenidas en el Corpus Iuris, y por otra, la gran influencia que en toda la vida intelectual y social de la baja Edad Media proyectará la Iglesia Católica, ${ }^{27}$ tanto a través de la doctrina de los teólogos como por el auge de los principios manifestado en el pujante esfuerzo creador de los canonistas. ${ }^{28}$

Nos permitimos recordar el bien conocido esquema de las fuentes de las obligaciones que propone Gayo en sus Instituciones 3.88, donde clasifica las que "nacen de contraerse" frente a las que "nacen de delinquir": él mismo seguidamente descalifica ese esquema cuando se niega a incluir la obligación de devolver lo que se ha solucionado indebidamente, entre las obligaciones que "se contraen por la propiedad" (re). ${ }^{29}$ Por eso más tarde, en las Res Cottidianae, obra atribuida al mismo Gayo, aparece un tercer grupo de fuentes, dedicado a las obligaciones que nacen de "otras figuras causales", entre las que más tarde Justiniano distinguió "las que son como contratos" frente a "las que son como delitos". La culpa aquiliana y sus derivados fueron incluidos entre los delitos, pese a que la falta de necesidad de dolo debería haberlas llevado más bien a integrar el género de los "cuasidelitos": ${ }^{30}$ tal vez dicha incongruencia llevó, a las correspondientes acciones de daño, desde un tratamiento claramente delictual durante la época prejustinianea, a una consideración más alejada de estos principios en la doctrina medieval de glosadores, postglosadores, ${ }^{31}$ e inclusive en las Partidas.

27 Corral Talciani, Hernán, Lecciones de Responsabilidad Civil Extracontractual, Santiago, Editorial Jurídica de Chile Santiago, 2003, p. 83 ss.

28 Wesenberg, G. y Wesener, G., Historia del Derecho Privado Moderno, trad. de José Luis de los Mozos Toyúa, Valladolid, Lex Nova, 1998.

29 Gai. 3.89

30 Samper, Francisco, Derecho romano, 3a. ed., Santiago de Chile, Universidad Católica de Chile, 2013, p. 343.

31 Koteich, Milagros, Responsabilidad contractual y aquiliana. Revisión de una distinción tradicional con base en la culpa y su graduación, Tratado de Responsabilidad Civil 1, 2003, 5. Atinadamente señala esta autora que los glosadores, basados en la doctrina de santo Tomás de Aquino, consideraron inocua la acumulación de pena y daño. 
Hemos de recordar que la actio leges Aquiliae clásica, a excepción de su cumulatividad con una acción reipersecutoria, reúne todas las características de las acciones delictuales, cuales son la de la intransmisibilidad pasiva, la cumulatividad si los autores del daño son varios, y la noxalidad, cuando el delincuente es persona dependiente o esclavo. Estos mismos principios, desarrollados por los maestros medievales, según hemos visto, pasan al Derecho castellano y se plasman en las Partidas, ${ }^{32}$ de donde son tomados a través de una rica vía doctrinaria en nuestro ordenamiento jurídico nacional.

El problema de la previsibilidad no estará presente de manera explícita en estos nuevos planteamientos, pero tampoco será rechazado, y nada impide deducir que, tal como sucedía en el Derecho culto del Digesto y hasta en las concepciones romanovulgares, la cuestión seguía presente a través de la noción común de su estrecha relación con la culpa. Pero sin duda es este último concepto, el de la culpa, tan ligado a las exigencias morales de la sociedad medieval, que pasará a ocupar el primer plano del quehacer intelectual de los juristas. La idea central proviene de un conocido principio retomado y claramente expuesto por santo Tomás de Aquino apoyado este pensador en el ya conocido texto romano expresado en un pasaje de Ulpiano y en Instituta de Justiniano, ${ }^{33}$ y que presenta los tres axiomas básicos de lo que podríamos llamar la moral jurídica: "Honeste vivere, alterum non laedere, suum cuique tribuere" (Vivir honestamente, no dañar al prójimo, atribuir a cada uno lo suyo). Incide santo Tomás en el segundo de ellos, para recalcar que todo daño injusto ha de ser reparado, ya que "el hombre está obligado a la restitución de aquello en que causó un perjuicio a otro". ${ }^{34}$

La doctrina medieval encontrará su desarrollo a través de la obra de los glosadores — siglos XII y XIII- y de los comentaristas o "bartolistas" - siglos XIV y XV. Por influencia canónica, el punto de vista para la configuración del que hoy llamamos cuasidelito de daño se

32 Partidas 7.15.2, 7.15.15

33 D. 1,10 , pr, Inst. 1,1,3.

34 Tomás de Aquino, Suma teológica. Edición dirigida por los Regentes de Estudios de las Provincias Dominicanas en España, Madrid, BAC 5, 2001, pp. 725-731. II-II, q. 62, p. 519. 
irá perfilando cada vez más firmemente sobre la idea de que la obligación de reparar no proviene tanto del daño inferido, sino del indebido actuar del responsable, o, dicho de otra manera, el elemento de la culpa se sobrepone en importancia al de la lesión, y sobre el hechor recae el deber de restituir aquello en cuanto perjudicó a otro, por cuanto es mediante la culpa que el hombre se separa de su propia razón de ser, de manera que la posibilidad de ser culpable es el mayor peligro para la existencia del hombre. ${ }^{35}$

\section{TRATAMIENTO EN LA ÉPOCA RENACENTISTA}

A partir de las ya expresadas bases, la doctrina renacentista, impulsada por los cultivadores del llamado "mos gallicus"36 y por los creadores de la escuela racionalista del Derecho Natural, entre los que sobresale especialmente el internacionalista holandés Hugo Grocio, exaltará los rasgos éticos de aquellas obligaciones que provienen del daño, ya que la reparación que culpablemente se causa a otro, es un deber moral que por imperativo de la razón se transmite al campo jurídico como obligación de derecho natural. La doctrina de Grocio así será decisiva en el desarrollo de la configuración posterior del cuasidelito de daño. En su obra capital De Iure Belli ac Pacis enuncia la siguiente regla: "Llamamos maleficio a toda culpa, provenga de hacer o de no hacer, contraria a aquello que los hombres deben hacer ordinariamente o por razón de cualidad cierta". ${ }^{37}$ La obra de Grocio tendrá decisiva influencia en el pensamiento de Dumoulin que aborda de lleno el problema de la previsibilidad.

\section{CODIFICACIÓN Y SUS ANTECEDENTES RELATIVOS}

\section{A LA PREVISIBILIDAD}

La teoría de los daños previsibles fue expuesta por Dumoulin en el siglo XVI en el número 60 de su "Tractatus de eo quod interest". Sin

35 Pieper, Josef, Las virtudes fundamentales, 9a. ed., Madrid, Rialp, 2017, p. 27.

36 Wesenberg y Wesener, 1998, pp. 109 y ss.

37 Grotius, H., De Iure Belli ac Pacis, Lib. II. cap. XVII, n. 1. 
embargo, un siglo más tarde quien la desarrollará extensamente será Domat para posteriormente ser perfeccionada por Pothier durante el siglo XVIII y finalmente codificada a principios del Siglo XIX. ${ }^{38}$

Así las cosas, el aporte más decisivo para la comprensión de nuestro problema proviene de Jean Domat, quien establece una distinción que tiene precedentes como lo acabamos de señalar, pero que se reproducirá en él provista de un énfasis y proyección antes no advertidos. Individualiza este jurista, aparte de los crímenes y delitos, dos clases de hechos capaces de producir daño, cuales son en primer lugar, el incumplimiento de las obligaciones establecidas a través de un acto convencional o contrato, y en segundo lugar, los que no provienen de convenciones, pero que tampoco configuran crímenes o delitos, como sucede en el caso que él ejemplifica con el edicto "de effussis vel deiectis" o daños no intencionales causados por las cosas que se arrojan desde una ventana de manera descuidada: a esta categoría de hechos consistentes en daños culpables pero no intencionales, le dará este jurista el nombre genérico de "cuasidelitos", con que ya precedentemente se había designado a ciertos hechos culposos. ${ }^{39}$ En la obra de Domat se declara más expresamente, y con un sentido más abiertamente dirigido al Derecho como ciencia práctica, que "todas las pérdidas y todos los daños que pueden sobrevenir... por imprudencia, ligereza o ignorancia de lo que debe saber... deben ser indemnizados por aquel cuya imprudencia o falta haya dado lugar". ${ }^{40}$

Lo más relevante para nuestra tesis en lo referente a la distinción que propone Domat entre "daños que proceden del incumplimiento de un contrato", y los que "sin ser crímenes o delitos no provienen de convenciones", vendrá a ser la circunstancia de que junto con esta clasificación introduce otra, entre perjuicios "mediatos" (directos) $e$ "indirectos", y a la vez respecto de los directos distingue los daños "previstos" de los "imprevistos", y limita la posibilidad de indemni-

38 Barrientos Zamorano, M., "Los daños extrapatrimoniales que se previeron o pudieron preverse al tiempo del contrato", Revista Chilena de Derecho, vol. 34, núm. 1, 2007, p. 12.

39 Samper Polo, Francisco, Derecho romano, Santiago, Ediciones Universidad Católica de Chile, 2007, pp. 342 y ss.

40 Domat, J., Las leyes civiles en su orden natural, trad. de José Taulo Vilarrubias y Sarda, Barcelona, 1844. 
zación, cuando hay culpa y no dolo, solo a los daños previstos. ${ }^{41}$ De esta manera, de la obra de Domat pasará a Pothier, ${ }^{42}$ inspirador del Code Napoleon.

Esta limitación de la previsibilidad de los daños al solo ámbito contractual no tiene precedentes en las fuentes romanas, pero será plasmada normativa y específicamente en el artículo 1150 del Code Napoleon que señala:

Le débiteur n'est tenu que des dommages et intérets qui ont été prévus ou qu'on a pu prévoir lors du contrat, lorsque ce n'est point par son dol que l'obligation n'est point exécutée ("El deudor solo estará obligado al pago de daños e intereses previstos o que hubieran podido ser previstos en el momento del contrato, cuando en el incumplimiento de la obligación no existiera dolo de su parte"). ${ }^{43}$

En relación a esta norma ya resaltaba con gran acierto desde antiguo Planiol al decir que: "En el Code la exclusión del artículo 1150 (que allí establece la exigencia de previsibilidad de los perjuicios) en materia de delitos y cuasidelitos introduce una diferencia, la única que es real, entre las dos especies de culpa". ${ }^{44}$ Por su parte, en el artículo 1382 que indica: "Todo caso cualquiera del hombre que causa al prójimo un daño obliga a aquel por cuya falta acaeció a repararlo" y en el 1383 que plasma: "Cada cual será responsable del daño que cause no solamente por su actuación, sino también por su negligencia o por su imprudencia", se recoge casi a la letra aquel principio ya sugerido por santo Tomás conforme al cual se responde por "todo daño", o para decirlo más exactamente, por "todo hecho del hombre que causa daño a otro". ${ }^{45}$

41 Domat, 1844, p. 76.

42 Pothier, J., Tratado de las obligaciones, Buenos Aires, Heliasta, 1843, pp. 470 y p. 480 .

43 Citado por Cristian Banfi del Río, "Por una reparación integral del daño extracontractual limitada a los hechos dolosos o gravemente negligentes", Revista Ius et Praxis, núm. 2, 2012, p. 4.

44 Domínguez Hidalgo, C., "Algunas Consideraciones en torno al daño como elemento de la responsabilidad civil", Revista de Derecho de la Universidad Católica de Valparaíso, vol. XIX, 1998, p. 241.

45 Corral, 2004, p. 81. 
LA ÉTICA DE ARISTÓTELES EN LA EVOLUCIÓN DE LA CULPA JURÍDICA...

El contenido pasará al artículo 2329 del Código de Bello que reza: "Por regla general, todo daño que pueda imputarse a malicia o negligencia de otra persona, debe ser reparado por ésta...", y de la misma manera que en esta norma queda establecido el principio de la indemnización por culpa extracontractual, lo relativo a los contratos quedará plasmado en el artículo 1558 del Código Civil que indica:

Si no se puede imputar dolo al deudor, solo es responsable de los perjuicios que se previeron o pudieron preverse al tiempo del contrato; pero si hay dolo, es responsable de todos los perjuicios que fueron una consecuencia inmediata o directa de no haberse cumplido la obligación o de haberse demorado su cumplimiento...

y así el factor de la previsibilidad, tanto en el Código francés como en el chileno, aparece solo ligado a la culpa contractual, ya que cuando se trata de la extracontractual, simplemente se alude a "todo daño", sin especificar si es o no previsible. ${ }^{46}$

A nuestro parecer, y tal como lo hemos ya sugerido, el verdadero sentido de las palabras "todo daño" no es sino la expresión de aquella doctrina antigua y medieval ya contenida en la escolástica y en la obra de Grocio, y que no incluía el propósito de establecer una diferencia entre la culpa contractual y extracontractual; sin embargo, la lectura del pasaje tomado del Tratado de las Obligaciones, nos muestra que el sentido que atribuye Pothier a estos antecedentes históricos, no es exactamente igual al significado primigenio, ya que tanto santo Tomás como Grocio pretendían simplemente decir que habiendo culpa, todo daño debía ser reparado. Así las cosas Pothier, heredero del pensamiento de Domat, entendió que con la expresión "todo daño" se quería decir que en materia de culpa aquiliana no se debían hacer distinciones apoyadas en la previsibilidad, y con este

46 Punto de vista diverso sobre el iter histórico que da forma a estas disposiciones: Javier Barrientos Grandon, "De la presunción general de culpa por el hecho propio. A propósito de los artículos 2314 y 2329 y de nuestro "código civil imaginario" (II)", Revista Chilena de Derecho Privado, 13, 2009, pp. 9-94, 4 y ss. El autor adelanta una inteligente y meditada conjetura sobre los posibles antecedentes hispano-indianos de las citadas normas. La controversia merece un estudio que excede los límites de este trabajo. 
sentido novedoso o distorsionado quedó plasmado el concepto tanto en el Code Napoleon como en todos los en él inspirados, el nuestro entre ellos, de manera que se caracterizan en esta materia por tratar en apartados distintos las configuraciones legislativas de la responsabilidad contractual y extracontractual. La doctrina se ha esforzado en procurar desentrañar las razones de esta dualidad de sedes, y ha concluido que efectivamente la única diferencia significativa estriba en que para el caso de la culpa extracontractual no se exige el elemento de la previsibilidad. ${ }^{47}$

\section{CONCLUSIONES}

Nuestro trabajo ha tenido como finalidad ahondar en la evolución de la culpa desde el nacimiento de ésta en la filosofía aristotélica, desarrollando luego, una estructura técnica en el Derecho Romano, posteriormente retomando su esencia en la Edad Media, dándole un sentido racional en el Renacimiento para finalmente advertir el panorama de este factor de atribución en la codificación decimonónica.

Las miradas hacia la culpa son amplias y suscitan variados intereses, cuestión tratada en este breve estudio, en donde podemos observar distintas visiones desde la religión, la filosofía y el derecho. Es así, como en el desarrollo de esta investigación hacemos hincapié en la previsibilidad como componente de la culpa que hoy llamamos extracontractual.

Este elemento - el de la previsibilidad- ya fue advertido por el Estagirita y en Quinto Mucio Scaevola se convierte en un requisito indispensable de tal factor de atribución. En el derecho intermedio más centrado en los aspectos morales que en los propiamente jurídicos, la consideración de este rasgo pasa a segundo plano, lo cual no significa que se prescinda de él, para reaparecer pujante en la Edad Moderna y en la codificación.

En consecuencia, la noción de culpa aristotélica se encuentra en el fundamento de la trilogía de normas que forman parte del sustento de la culpa aquiliana en nuestro Código Civil, a saber, los artículos 2314,2329 y 2330 . Bello sigue en esta materia a los tratadistas fran-

47 Banfi del Río, 2012, pp. 15 y ss. 
ceses quienes a su vez codifican este elemento profusamente apoyados en fuentes romanas. Semillero que tiene sus cimientos en la Grecia del siglo IV a. C.

\section{REFERENCIAS}

Aedo Barrena, Cristián, "Raíces griegas de la noción romana de culpa”, Revista de Estudios Histórico-Jurídicos, núm. 35, 2013.

Aquino, Tomás de, Suma teológica. Edición dirigida por los Regentes de Estudios de las Provincias Dominicanas en España, Madrid, BAC 5, 2001.

Aristóteles, Ética a Nicómaco, 2a. ed. Madrid, Tecnos, V. 1132 a. 7

BANFi DEL Río, Cristian, "Por una Reparación Integral del Daño Extracontractual Limitada a los Hechos Dolosos o Gravemente Negligentes", Revista Ius et Praxis, núm. 2, 2012, p. 4.

BARRIENTOS GRANDON, Javier, “De la presunción general de culpa por el hecho propio. A propósito de los artículos 2314 y 2329 y de nuestro "código civil imaginario" (II)", Revista Chilena de Derecho Privado, núm. 13, 2009.

BARrientos Zamorano, M., "Los daños extrapatrimoniales que se previeron o pudieron prever-se al tiempo del contrato", Revista Chilena de Derecho, vol. 34, núm. 1, 2007.

BARros Bourie, Enrique, "La responsabilidad civil como derecho privado”, Estudios Públicos, núm. 112, 2008.

Castresana, Amelia, Nuevas lecturas de la responsabilidad aquiliana, Universidad de Salamanca, 2001.

CoRral TAlCiAnI, H., Lecciones de responsabilidad civil extracontractual, Santiago, Editorial Jurídica de Chile Santiago, 2003.

DodDs, Eric, Los griegos y lo irracional, trad. de María Aranjo, Madrid, Alianza Editorial, 1951.

Domínguez HidAlgo, C., "Algunas consideraciones en torno al daño como elemento de la responsabilidad civil", Revista de Derecho de la Universidad Católica de Valparaíso, vol. XIX, 1998. 
Domat, J., Las leyes civiles en su orden natural, trad. de José Taulo Vilarrubias y Sarda, Barcelona, 1844.

Ferrater Mora, J., Diccionario de filosofía, Madrid, Alianza, 1990.

GARcía-HuIDOBRo, Joaquín, La recepción de la doctrina aristotélica de lo justo natural y lo justo legal en los comentaristas medievales de la Ética a Nicómaco, Buenos Aires, Tesis doctoral presentada en la Facultad de Derecho de la Universidad Austral, 2015.

Grotius, H., De Iure Belli ac Pacis. Lib. II. cap. XVII, n. 1.

GuZMÁn, A., Derecho privado romano, 2a. ed., Santiago de Chile, Legal Publishing.

GuZmán, A., Historia de la codificación civil en Iberoamérica, Thomson Aranzadi, 2006.

Inostroza AdAsme, Sonia, "La previsibilidad en la culpa Aquiliana: ¿evolución o involución? Una revisión doctrinaria y jurisprudencial", Revista de Derecho, Universidad Católica del Norte, vol. 27, 2020.

KLÜBER, Bernhard, Der Einfluss der griechischen Philosophie auf die Entwicklung der Lehre von den Verschuldensgraden im römischen Recht, Berlín, 1930.

Koteich, Milagros, "Responsabilidad contractual y aquiliana. Revisión de una distinción tradicional con base en la culpa y su graduación", Tratado de Responsabilidad Civil, 1, 2003.

LACroix, Jean, Filosofía de la culpabilidad, trad. de A. Martínez. Revista Barcelona, 1977.

D’ORs, Derecho privado romano, 3a. ed., Pamplona, EUNSA, 1977.

PIEPER, Las virtudes fundamentales, 9a. ed., Madrid, Rialp, 2017.

Pothier, J., Tratado de las obligaciones, Buenos Aires, Heliasta, 1843.

Ricoeur, Paul, El conflicto de las interpretaciones, trad. de Alejandría Falcón, Fondo de Cultura Económica, 2008.

SAmper Polo, F., Derecho romano, Santiago, Universidad Católica de Chile, 2007.

Wesenberg, G. y WeSEnER, G., Historia del derecho privado moderno, trad. de José Luis de los Mozos Toyúa, Valladolid, Lex Nova, 1998. 